\title{
Cultural Analysis of Tourism Landscape in Yantai Nanshan Mountain
}

\author{
Haifeng Dai \\ School of Arts \\ Yantai Nanshan University \\ Longkou, Shandong, China 265713
}

\author{
Hongyan $\mathrm{Yu}$ \\ School of Arts \\ Yantai Nanshan University \\ Longkou, Shandong, China 265713
}

\begin{abstract}
Finding aesthetic, appreciating aesthetic and feeling aesthetic are the main feelings when people travel around. Tourism landscape culture becomes an objective image of developing featured tourism service and featured landscape designs enhance the connotation of sightseeing places. Therefore, research on tourism landscape culture of distinction, uniqueness and humanity becomes a significant technological factor to lead and support tourist industry advancing with times. To develop Nanshan Mountain is a large scale tourism project on the basis of understanding of historical culture and regional culture along with China's reform and opening-up policy. As the time goes by, tourism landscape culture develops with inheritance. Based on analysis of Longkou tourism resource and study on current situation of Nanshan Mountain tourism, this paper aims to improve the analysis of Nanshan Mountain tourism landscape culture in order to promote further research on the regional landscape culture.
\end{abstract}

Keywords-Nanshan Mountain; tourism; landscape culture; tourism landscape

\section{RESEARCH AND ANALYSIS OF BACKGROUND OF NANSHAN MOUNTAIN TOURISM}

\section{A. Analysis of Longkou Tourism Landscape}

1)Longkou tourism landscape resources : Shandong province covers many unevenly-distributed tourism resources, of which Yantai city shares one of the most rich tourism resources.Hence, Yantai enjoys potential development prospect in tourism. Longkou, as one of the most developed areas in Shandong, well-known as "Golden yellow connty", boasts a long history with abundant resources, strong economic strength and advantageous geographical location.

Longkou is located in the middle north of Shandong peninsula, with a north neighbour of Bohai Sea. The terraced relief of Longkou shows from high low-height hills in the southeast to low coastal plain in the northwest. Across the Bohai Sea is Tianjin and Dalian. Adjacent to Penglai in the east, to Qixia and Zhaoyuan in the south, Longkou has temperate monsoon climate, without bitter-cold winter and without sweltering summer. Longkou has four distinctive seasons with pleasant weather.
Longkou city enjoys a long history and abundant cultural heritage. Before Xia Dynasty, it was called Yuyi, belonging to Qingzhou state. In Shang Dynasty it belonged to Yingzhou state. In the end of Shang Dynasty, it developed into Laiguo state. In Qin Dynasty, the government set up Qijun prefecture and began to set up Huangxian County, which was one of the earliest county-government regions in China."1

Historical tourism resources: according to statistics, Yuezhu temple was built in Laishan governed by Longkou. The temple was one of eight temples set up during First Emperor of Qin's three east China tour after he unified China. According to emperor Kangxi- edition Huangxian county annals, the name of Longkou was firstly recorded in Ming Dynasty in which Longkou was a fishing village. "Boats from north frequently come here to sell grains and boats from south in most cases paper and sugar" , which is the authentic depiction of Longkou's history. Weathered by five thousand years, Longkou has left many historical sites and human civilization, which adds certain mystery and secrets to Longkou itself. Loukong has seen many famous figures in history: a great statesman and thinker Chun-Yu Kun in Warring State Period, a famous alchemist, who went to the sea eastwards with thousands children, grains and craftsmen and firstly created relationships among China, Japan and Korea in Qin Dynasty, a famous general Tai-Shi Ci from Kingdom of $\mathrm{Wu}$ in Three Kingdoms Period, one of founding fathers in Ming Dynasty $\mathrm{Hu}$ Dahai, an incorruptible and intelligent minister Wang Shizhong, the cabinet minister Fan Fucui and a painter Jiangyin in Ming Dynasty, a director of the Board of Rites Jia Zhen, a member of the Imperial Academy Wang Shouxun in Qing Dynasty, a calligrapher, seal cutting expert and paleographer Ding Foyan in the early of Republic of China(1912-1949) etc. Longkou is one of amazing birthplaces of heroes and great man. Over one thousand years' Donglai culture, ancient buildings and historical sites, historical figures, holy land relics, traditional customs and other tourism resources and the inherited cultural history have extremely high value of cultural tourism. Longkou is a holy place for people to find ancient historical civilization. "Life changes ups and downs. Future would become history. There are places of interest left by ancestors.

\footnotetext{
${ }^{1}$ Li Peijun et al. Preliminary Report of General Plan of Longkou City[R]. Longkou City Government 2012. (5).
} 
We revisit the attractions nowadays". The poem was composed by Meng Haoran in Tang Dynasty, which is a perceptive recognition on historical site-oriented tourism.

Modern tourism resources: "'culture is romantic economy, and economy is concrete culture '.Culture interacts with economy, which brings a win-win situation. In short, regional culture strength, formed by time-honored cultural deposits, far-reaching cultural atmosphere, and gentle deposition of culture and charming as trickling water, is increasingly becoming an incentive source of regional culture development." ${ }^{2}$ With the reform and opening up, Longkou city's economy is increasing day by day with coordinated improvement of social activities. Nowadays, Longkou ranks the top 100 county in terms of country general strength, ranks number one among Shangdong top100 counties and ranks 11 th among China's top-100 counties.

Longkou, with picturesque scenery, pleasant climate, land with honey and milk and solid cultural foundation, is located in the frontier of Shandong peninsula where traditional Chinese people experience circles of life generation by generation. Longkou is a birthplace of Donglai culture and it shares the long coastal line, blue port, developed transportation and convenient thoroughfare to the sea... Longkou is one of the important parts of China's eastern coastal and Bohai Sea's economic belts with a significant import-and-export location and an important place to South Korean and Japanese enterprises. Migrated groups from northeast of China, Beijing, Tianjin, Hebei, other places of Shandong, South Korea and Japan constitute the main suburban and rural residents in different local regions. In Longkou, the azure sky is like a pasture of white cloud, the deep-blue sea is like a land of boats and ships and the grassy orchard like an assembly of hills and mountains. There still exists traditional religions, ancient buildings and tranquil gulfs $\cdots$ all of these beautiful pictures make us feel life's praying from religious worship, feel historical track from traditional buildings and feel claiming for resources from the sea from scattered fishing boats. Longkou enjoys a tranquil, serene, simple and pristine beauty with unique coastal charming and special historical culture, which distinguishes itself from other costal cities with noise and hubbub. Therefore, Longkou boasts the honor of "China's excellent tourism city".

\section{2) Features of Longkou tourism resources}

a) The solid historical culture generated from traditional historical development: Longkou has a long history with renowned celebrities, official's visits, revolution's involvement and famous ancient merchants, which leaves evidence-founded historical inheritance, accumulates rich historical culture and forms unique foundation of historical cultural tourism.

b) Abundant folk-custom culture formed by geographic atmosphere: Longkou culture belongs to a part of Qi and Lu culture. In ancient time, Longkou was seldom affected by other factors for the remote geographic location.

${ }^{2}$ Qu Yuwei. The Hometown of Xufu[Z]. Jiaodong Online, 2009 (1).
Thus, the traditional customs are well conserved and come down in the same source of Qi and Lu culture. However, in terms of building, costume, wedding, funeral, sacrifice, festival, art and food etc, Longkou has its own coastal cultural and regional cultural deposits.

c) Harmony of ecological unification: In Longkou, there are mountains, hills, plains and coastal areas with even-located rivers and distinctive rural zone and city zone. The modern agricultural development is in large-scale with local characteristics. And there is a promising future of tourism resources' development in respects of country and ecology. In 2013, the local municipal government proposed a construction goal of "ecological Longkou".On May 26th 2014, the fourth National Ecological Tourism Cultural Industrial Development Peak Forum held in Shenzhen. In accordance the assessment standard of over $50 \%$ forest coverage, vegetation cover, water quality in city and country, wetland preservation and ecological diversity etc, Longkou city was chosen "top 100 of China's care-free breathing town", ranking the 61st, which totally proves Longkou's prominent achievement in ecological unification and harmonious development.

d) The celebrity of coastal culture: Longkou is surrounded by sea in two sides. Thus, it has developed fishing industry. Particularly, in recent years, marine aquaculture industry and fisherman's family tourism promote the development of costal tourism. Costal entertainment, bathing in the sea, rowing boats, wharfing sightseeing, purchasing seafood and traveling on ship etc become tourism crazes.

3) Current situation of Longkou tourism development: Longkou, located first-tier tourism circle around Bohai Sea and as a golden place of coastal tourism zone in Shandong province, enjoys a natural favorable geographical location against mountains and neighboring sea. Since many years ago, Longkou shares the established honor of "In south are Suzhou city and Hangzhou city, in north are Penglai and Huang county" in folk, which has long enjoyed a good reputation of tourism and resort vacation paradise in China.

However, the development of tourism is uneven. There is only one rating 5A tourist attraction until now. Several historical and potential tourism resources have not yet developed. Thus, the polarity gap is big and the development is not coordinated, which negatively affects Longkou's whole tourism scale. In 2012, Longkou's general city planning put forward to constructing new tourism development mode: expanding around city, westwards relocation of the main city $\cdots$ to build resort district in southern mountain area and to develop eastern costal tourism economic zone and Longgang port tourism economic zone $\cdots$, which provides foundation for further tourism development in Longkou.

\section{B. Analysis of Nanshan Mountain}

1) Current situation of Nanshan Mountain tourism resources: Nanshan Mountain tourism is one of the industries of Nanshan Mountain Group. Nanshan Mountain, 
located in the southern mountain area of Longkou and north coastal zone, combined with ancient relics, guided by respecting history, high standard, quality orientation, is based on restoration of ancient buildings and on expansion project. Then the Nanshan Mountain becomes a national rating 5A tourist attraction with natural landscape and human landscape. With an area of 20 square kilometers, the attraction has four main sections: Chinese religious cultural park, Chinese historical cultural park, happy valley - theme part and eastern tourism resort vacation zone.

2) Characteristics of Nanshan Mountain tourism resources:

a) Harmonious coexistence of natural landscape and human landscape

Nanshan Mountain tourism reflects the characteristic of harmonious coexistence of ecological natural landscape and abundant human landscape. Based on natural scenery of Lushan Mountain and coastal landscape, guided by the principles of adjusting measures to local conditions, making the best use of the circumstances, Nanshan Mountain develops a tourism landscape planning. Meanwhile, on the foundation of historical culture, it is necessary to deeply explore the regional religion, history and coast cultural connotation in order to make harmonious coexistence and closeness between nature and human, reflecting a reasonable layout and manifesting its characteristics.

b) )Taking regional historical culture as media

"Tourism culture is the soul of human resources. It is significant for a landscape's development to how we fully explore the cultural connotation contained in the human landscape." 3 Nanshan Mountain tourism takes local historical religious relics and regional culture as a foundation to develop the religious cultural essence of Buddhism, Taoism and Confucianism. To take Chinese historical culture from ancient time to Qing Dynasty as the longitude, to take blessing, longevity, auspiciousness culture as the latitude and to take local people's customs and fashion sports as a media to create a regional feature landscape of coastal folk-custom culture and entertainment culture.

\section{c) Complete tourism industrial chain}

Nanshan Mountain tourism contains ornament from ancient time and modern time and absorbs Chinese civilization, which has developed into an integrated comprehensive tourism industrial system with industrial sightseeing, resort and relaxation, learning and education, sacrifice and worship, top-level business, convention and exhibition, sports and fitness, entertainment and shopping and industrial tourism. The system depicts a picturesque scenery of "enjoying auspiciousness and longevity in Nanshan Mountain and it is a place where tranquilizes your mind" on earth.

\footnotetext{
${ }^{3}$ Huan Zhanwei. Preliminary Discussion on Tourism Culture Carrier of Human Landscape[J] Guilin: Guilin Institute of Tourism .2004.6
}

\section{d) Keeping a foothold in local features}

To attach great importance to explore Longkou culture's features in order to highlight the local religious culture, traditional culture, folk-custom culture, costal culture and golf culture etc. and to make the Jiaodong regional culture connotation stand out, to create Nanshan tourism brand image and to inherit the Nanshan Mountain cultural deposits of auspiciousness and longevity.

\section{LANDSCAPE CUlTuRE OF NANSHAN MOUNTAIN TOURISM}

\section{A. Historical Culture}

"Historical cultural resources are the important foundation of regional cultural development construction. Meanwhile, the resources provide tourism culture industrial development with guarantee". 4 Taking history as the longitude and taking culture as the latitude, Nanshan Mountain tourism create featured historical cultural tourism landscape, which could be summarized in three respects.

Chinese history: taking Chinese history as a main structure, Chinese historical culture park shows Chinese five thousand years historical culture from ancient time to Qing Dynasty. By designs of numerous building landscapes, human landscapes and authentic material landscapes, they develop into the first Chinese historical landscape tourism system in China. The park is the sole large-scale theme park utilizing history and auspicious culture as subject in China. So the park is like a vivid general history of China, fully demonstrating Chinese five thousand years' splendid and brilliant historical civilization.

Religious history: Nanshan Mountain was called Lushan Mountain in ancient time. According to emperor Kangxiedition Huangxian county annals (1673): The mountain is solemn and the water is icy. In spring, pines on the mountain grow green. In autumn, the leaves of persimmons turns deep red, which likes the immortal are painting the dots with magic power." The Nanshan Mountain has been honored “Donglai's first mountain". In history, Lushan Mountain had many temples, such as Lushan Taoist temple in Jin Dynasty, Lingyuan Taoist temple in North Song Dynasty, Shiquan temple and Dingqing Buddhist temple in Tang Dynasty, Xiangshui nunnery and Qikuang nunnery in Ming Dynasty etc. In Jin Dynasy, a Taoist disciple in Lushan Taoist temple took an elixir then became an immortal. Thus, in Sui Dynasty the Lushan Taoist temple changed into "Shengtian(go up to heaven) Taoist temple" and in Tang Dynasty it changed into "Xianjun(immortal) Taoist temple". And an emperor Shenzong of Song Dynasty granted a horizontal inscribed board read "Yanzhen(prolong life) palace". The traditional ballad reads:"talking about Shandong province and Huangxian County, there is a Lushan Taoist temple in the south city. The mountain is green and the water is clean, attracting five dragons to make the temple shiny. The temple is created without column, with an arc in

\footnotetext{
4 Li Fusheng The Importance of Historical and Cultural Resources for Regional Development [J] Qinhuangdao: Tourism Overview .2012.5.
} 
down-to-up sequency. There are five dragons in a well in front of the gate. Each of them fly upwards swiftly." The ballad depicts the grandness and mystery of Lushan temple. These days, taking Lushan religious historical culture as a foundation, the religious cultural park has been built by expansion project mainly based on historical relics, including Nanshan meditation temple, Nanshan Taoist temple, Xiangshui nunnery and Huanyanshijie etc.

Pioneering work's history of Nanshan Mountain: Guided by the reform and opening-up policy, Nanshan Mountain people experience from earning life by farming to industrial and subsidiary business. This road is a creative innovation and an example for starting a business to become rich in rural areas in China. Taking Nanshan Mountain's development history as a landscape, through Nanshan Mountain's and Xiaokangnanshan Mountain's development historical periods, Nanshan Mountain compound courtyard designs an enterprise historical culture by buildings, authentic materials and statistics.

\section{B. Religious Culture}

For thousands of years, ancient people regarded Lushan Mountain as a geomantic place and a holy place to attract religious culture. Thus, it appealed many people to pray for the immortals, learn the way of life and warship the Buddha. And there are many hymns left. In Ming Dynasty, Lushan Mountain Four Miracles by Fan Fucui wrote:"with gentle wind the cloud is wandering, and sounds of nature means the sunset is coming. The scene of rivulet and flowers by the bridge makes me happy, seeing a woodcutter is returning (see emperor Kangxi- edition Huangxian county annals)." Therefore, there is not only a wonderful historical legend, but also a time-weathered representative of Dongyi culture Laiziguo Country culture. The legend and the culture are interwoven with each other, composing a beautiful historical picture. Thus, it is a Buddhism cultural holy place for people to bless for auspiciousness and longevity.

On the basis of deep-exploration of traditional historical culture, Nanshan Mountain group takes advantage of the rich religious cultural deposits in Lushan Mountain, making a large investment in restoration and expansion on original historical buildings. And they become a religious cultural park demonstrating the extensive and profound Buddhism culture, abundant and colorful religious culture and severalthousand years Confucianism. The biggest tin-bronze seated Buddha statue in the world is placed among mountains with graveness and solemnity. There is still another biggest indoor pharmacist jade Buddha statue. The two statues are highlights in the scenery.

\section{Folk-custom Culture}

Folk-custom is a kind of historical cultural heritage generated from regional people's life, habit, feeling and religion. Folk-custom refers to many contents, including various activities and behaviors in people's daily life. Folkcustom tourism is a process for people to experience a region's folk-custom culture and is a soul to develop regional tourism characteristics.
Longkou, for its special geographical position and environment, develops a folk-custom tourism characteristic to manifest local features. Longkou municipal government proposes a development idea of "ecological tourism" taking Nanshan Mountain tourism as a main part, taking city and country folk-custom activities as a connection line and taking festival activities as points to integrate religious, historical and revolution culture in order to build up Longkou folkcustom cultural tourism characteristic.

\section{Sport Culture}

Sport tourism is a new-age tourism product and a newparticipating-leisure-style tourism developed from traditional sports. Keeping a foothold in top-level sports tourism landscape development and construction, Nanshan Mountain tourism has built some characteristic landscapes including golf sports tourism, on-the-sea sports tourism and equestrian sports tourism.

Wandering in mountains and seas, swinging on Nanshan Mountain" is a summarized depiction of Nanshan Mountain golf sports tourism culture. There stands eleven golf clubs, which is a national golf team's training base. In 10 years, it has been granted to hold the Asian Nanshan Mountain - Chinese Master Tournament Course. Thus, it gradually develops into golf tourism culture integrating golf sport, course travelling, links, sports experiencing and social activity. In terms of on-the-sea sports, the wide coastal bathing beach and the sea yacht park develop new on-the-sea tourism product. The equestrian club makes tourists experience the Chinese traditional equestrian competitive sports "hitting polo" and enjoy the pleasure of gallop.

\section{E. Coastal Culture}

Apart from religious historical cultural deposits and genial life's vitality in this wonderland, the beautiful east sea coastal ten-thousand mu pine forest, the moon gulf bathing beach, east sea Buddism goodness Guanyin blessing, campfire party, Jiaodong yangko (a popular rural folk dance) wharfing sightseeing, fishing on the sea, and catching crabs etc. are the real landscape pictures of Jiaodong fishers and local people's life style and customs. The scenery forms various coastal tourism cultural landscapes of leisure, food and catering and entertainment.

In 2014, Nanshan Mountain east sea coastal tourism compound, as first 6 published coastal tourism compounds, entered for the next round of completion of "wonderland coast".

\section{F. Auspicious and Longevity Culture}

Respecting the aged and taking care of children is the Chinese traditional virtue, which develops an undertaking in Nanshan Mountain. There are senior citizen-oriented keeping-fit valley projects, like international leisure and rest center, keeping-fit valley hospital, university for the aged, the sun artistic square equipped with facilities. And there are activities like to establish senior citizen's association, the sun art troupe and other organizations, to hold international longevity cultural festival, senior citizen's artistic cultural 
festival and other major activities... Such as what the president Song Zuowen send word to senior citizen's cultural activities: "Let's start from Nanshan Mountain to make the senior citizens' live more quality, dignity, happy and spacious life". In Nanshan Mountain people can realize the fact that the elderly will be looked after properly, the elderly could have someone to count on and the elderly could have happy life. The auspicious connotation of "May your fortune be as boundless as the East Sea and may you live a long and happy life" will come true in Nanshan Mountain.

\section{REFERENCES}

[1] Li Peijun et al. Preliminary Report of General Plan of Longkou City[R]. Longkou City Government 2012. (5).

[2] Qu Yuwei. The Hometown of Xufu[Z]. Jiaodong Online, 2009 (1).

[3] Li Peijun et al. Preliminary Report of General Plan of Longkou City[R]. Longkou City Government. 2012. (5).

[4] Huan Zhanwei. Preliminary Discussion on Tourism Culture Carrier of Human Landscape[J] Guilin: Guilin Institute of Tourism .2004.6

[5] Li Fusheng The Importance of Historical and Cultural Resources for Regional Development [J] Qinhuangdao: Tourism Overview .2012 